\title{
Remote ischemic preconditioning for cardioprotection in elective inpatient abdominal surgery - a randomized controlled trial
}

Stefan Samad Antonowicz ${ }^{1,3}$ D , Davina Cavallaro', Nicola Jacques², Abby Brown², Tom Wiggins ${ }^{3}$, James B. Haddow ${ }^{3}$, Atul Kapila ${ }^{2}$, Dominic Coull ${ }^{1}$ and Andrew Walden² ${ }^{*}$

\begin{abstract}
Background: Perioperative myocardial injury (PMI) is common in elective inpatient abdominal surgery and correlates with mortality risk. Simple measures for reducing PMI in this cohort are needed. This study evaluated whether remote ischemic preconditioning (RIPC) could reduce PMI in elective inpatient abdominal surgery.

Methods: This was a double-blind, sham-controlled trial with 1:1 parallel randomization. PMI was defined as any post-operative serum troponin T (hs-TNT) $>14 \mathrm{ng} / \mathrm{L}$. Eighty-four participants were randomized to receiving RIPC ( 5 min of upper arm ischemia followed by 5 min reperfusion, for three cycles) or a sham-treatment immediately prior to surgery. The primary outcome was mean peak post-operative troponin in patients with PMI, and secondary outcomes included mean hs-TnT at individual timepoints, post-operative hs-TnT area under the curve (AUC), cardiovascular events and mortality. Predictors of PMI were also collected. Follow up was to 1 year.

Results: PMI was observed in $21 \%$ of participants. RIPC did not significantly influence the mean peak post-operative hs-TnT concentration in these patients (RIPC 25.65 ng/L [SD 9.33], sham-RIPC 23.91 [SD 13.2], mean difference 1. $73 \mathrm{ng} / \mathrm{L}, 95 \%$ confidence interval -9.7 to $13.1 \mathrm{ng} / \mathrm{L}, P=0.753)$. The treatment did not influence any secondary outcome with the pre-determined definition of PMI. Redefining PMI as $>5 \mathrm{ng} / \mathrm{L}$ in line with recent data revealed a non-significant lower incidence in the RIPC cohort ( $68 \%$ vs $81 \%, P=0.211)$, and significantly lower early hs-TnT release (12 h time-point, RIPC $5.5 \mathrm{ng} / \mathrm{L}$ [SD 5.5] vs sham $9.1 \mathrm{ng} / \mathrm{L}[\mathrm{SD} 8.2], P=0.03$ ).
\end{abstract}

Conclusions: RIPC did not at reduce the incidence or severity of PMI in these general surgical patients using predetermined definitions. PMI is nonetheless common and effective cardioprotective strategies are required.

Trial registration: This trial was registered with Clinicaltrials.gov, NCT01850927, 5th July 2013.

Keywords: General surgery, Ischemic preconditioning, Myocardial injury

\section{Background}

Perioperative myocardial injury (PMI) is defined as elevated cardiac enzymes after surgery with or without relevant symptoms or electrocardiogram (EKG) changes, and is proportionally linked to short-term mortality [1]. The incidence of PMI after inpatient abdominal surgery is

\footnotetext{
* Correspondence: andrew.walden@nhs.net;

andrew.walden@royalberkshire.nhs.uknhs.net

${ }^{2}$ Intensive Care and Anaesthetics, Royal Berkshire NHS Foundation Trust,

London Road, Reading RG1 5AN, UK

Full list of author information is available at the end of the article
}

common - 12-21\% - and is higher still in selected subgroups (e.g. gastro-oesophageal resection $>50 \%$ ) [1-3]. Cardioprotection studies in non-cardiac surgery have focused on clinical endpoints [4], using relatively hazardous interventions, such as medication or revascularization, in which harm outweighs benefit in lower risk patients [5-8]. However, given that PMI is also linked with adverse outcomes and is more common, new cardioprotection studies with biochemical endpoints and appropriately low-hazard interventions are needed.

(c) The Author(s). 2018 Open Access This article is distributed under the terms of the Creative Commons Attribution 4.0 International License (http://creativecommons.org/licenses/by/4.0/), which permits unrestricted use, distribution, and 
Remote ischemic preconditioning (RIPC) is a simple and safe procedure that may reduce ischaemia-reperfusion injury $[9,10]$. It involves temporary ischemia-and-reperfusion cycles to non-vital tissues, which may convey protective effects to distant sensitive organs. The specific mechanisms are incompletely understood, and may involve transcriptional reprogramming to cytoprotective cascades, and reduced radical release from the mitochondrial transition pore [11-13]. Harmful effects of RIPC seem limited to skin petechiae, which occur in 3-4\% and are self-limiting $[14,15]$. RIPC for cardioprotection has been investigated in cardiac [16], renal surgery [17], and vascular surgery [18], albeit with mixed results. However, whether RIPC influences PMI after abdominal surgery remains unknown.

We hypothesized that RIPC could reduce the frequency and severity of PMI after major abdominal surgery, and so we designed a sham-controlled randomized study to test this. The primary outcome measure was incidence of PMI (defined at our institution as $>14 \mathrm{ng} / \mathrm{L}$ ) within $72 \mathrm{~h}$ of surgery, and secondary outcomes were high-sensitivity troponin $\mathrm{T}$ (hs-TNT) area under the curve (AUC), cardiovascular events and mortality.

\section{Methods}

\section{Trial design}

This was a single-centre, double-blind, sham-controlled trial with 1:1 parallel randomization. The patient, the clinical team, and the investigator analyzing the data were blinded to the provided treatment. The trial was performed between October 2013 and December 2015 at the Royal Berkshire Hospital, Reading, United Kingdom, a medium-sized district general hospital. Ethical approval for the study was obtained from the National Research Ethics Service Committee South Central (Berkshire, ref.: 13/SC/0306), and the study protocol was deposited with ClinicalTrials.gov (NCT01850927, released 5th July 2013). The CONSORT checklist was followed for reporting [19].

\section{Participants}

Inclusion criteria were established as follows: (i) any patient undergoing a gastrointestinal or complex abdominal wall operation with expected admission $>1$ night (ii) $>45$ years of age. Exclusion criteria were patients (i) taking glibenclamide [20] (iii) with untreated hypertension (iii) with upper limb vascular disease or abnormal anatomy, including dialysis patients with arteriovenous fistulas (iv) unable to provide informed consent (v) participating in another cardiac trial (vi) recent diagnosis of infection (vii) elevated pre-operative hs-TnT. The consultant surgeon responsible for the patients care introduced the trial after confirmation of surgery. The research team took informed consent after the anesthetic pre-assessment visit, followed by baseline clinical and demographic data and a reference hs-TNT. Clinical cardiovascular risk factors were collected to predict PMI risk. The initial consideration was to develop the study as a pragmatic approach for clinical implementation, and so no restrictions were placed on the choice of surgical technique, and were at the discretion of the direct clinicians.

\section{Interventions}

Pre-operative anesthesia was conducted in the anesthetic anteroom and was protocolized: (i) intravenous access (ii) spinal/epidural anesthesia provision (iii) general anesthetic induction following pre-oxygenation (iv) airway intubation (v) commence RIPC treatment (vi) intra-arterial and further intravenous access on contralateral arm (vii) urinary catheter (viii) central venous access (ix) finish RIPC treatment (x) move patient to theatre. The anethesiologist responsible for the case carried out induction, intubation and maintenance of anesthesia. Anesthesia was predominantly maintained using desflurane; some received a continuous propofol infusion. There is data suggesting cardioprotective benefit for volatile anesthesia [21], and abrogation of RIPC effect by propofol anaesthesia [22, 23], and further data showing cardioprotective equivalence in cardiac surgery [24]. Therefore, a post-hoc comparison of the two techniques was favoured, rather than pre-specification of maintenance.

The study treatments were carried out by the operational investigators (DC, NJ, AB). A dedicated and regularly calibrated study sphygmomanometer (Durashock DS54, Welch Allyn) was applied to an arm. For RIPC, a pressure of $200 \mathrm{mmHg}$ was applied for $5 \mathrm{~min}$, followed by $5 \mathrm{~min}$ rest, for three cycles, totalling a 30-min treatment. The cuff for non-invasive blood pressure monitoring was placed on a leg or on the RIPC arm after the 30-min treatment. Sham-RIPC was identical in all aspects except that the release valve on the sphygmomanometer was open throughout, so that cuff pressure was always $<15 \mathrm{mmHg}$. The clinical team, participants and investigators responsible for data analysis (SA, TW, $\mathrm{AW}$ ) were thus blinded to allocation throughout the recruitment window.

\section{Outcomes}

The primary outcome was the mean peak post-operative hs-TnT within $72 \mathrm{~h}$ in patients developing PMI, as the best available PMI data in abdominal surgery used this endpoint and was used to power the study [1]. PMI was defined as any post-operative hs-TnT $>14 \mathrm{ng} / \mathrm{L}$ (cut-offs based on the 99th percentile of the local population; at our Institution, a clinically significant value is $>14 \mathrm{ng} / \mathrm{L}$ [25]). Assays were measured under research contract 
with the Institution's biochemistry department, using the 5th generation Elecsys system (Roche, Basel, Switzerland), complying to standard clinical-grade quality control and calibration procedures. Results were retained by the pathology department until the completion of recruitment and follow-up, and thus could not influence the usual clinical course. Blood samples were collected at 6 to $12 \mathrm{~h}, 24 \mathrm{~h}, 48 \mathrm{~h}$, and $72 \mathrm{~h}$. Secondary outcomes included mean hs-TnT at individual timepoints, hs-TNT area-under-the-curve within $72 \mathrm{~h}$, length of hospital stay, significant surgical complications within 30 days, and major adverse clinical cardiovascular events and all-cause mortality within 1 year. Specific (skin petechiae) and general serious adverse events were collected. Definitions for all outcomes are provided in Additional file 1. Data were collected at day of consent, day of surgery, day of discharge, and one-year follow-up. These were all direct encounters except for follow-up (telephone call or direct).

\section{Sample size}

Sample sizes were calculated using peak post-operative troponin data from the 2012 VISION paper and meta-analyzed estimates of RIPC efficacy in cardiac surgery $[1,26,27]$, as no studies have assessed the use of
RIPC in general surgery. We estimated mean peak hs-TnT rise in positive elective patients to be $30 \mathrm{ng} / \mathrm{L}$, with a standard deviation of $6 \mathrm{ng} / \mathrm{L}$. Meta-analyses at the time of study design reported an RIPC effect size of approximately $40 \%$ in patients undergoing cardiac surgery. With a two-tailed significance of 0.05 , power 0.8 , dropout rate of $5 \%$, and a significant (i.e. $\geq 14 \mathrm{ng} / \mathrm{L}$ ) hs-TnT rise occurring in $22 \%$ of patients this returns a recruitment target of 84 .

\section{Randomization \& blinding}

Patients were randomized using a sealed envelope system. A non-operational co-author (TW) randomly inserted 50 each of treatment and sham designations into 100 sequentially number envelopes. The allocation sequence was generated using a truly random number generator (based on atmospheric noise, www.random.org). The envelope was opened after intubation by the operational investigator performing the treatment $(\mathrm{DC}, \mathrm{NJ}, \mathrm{AB})$, and the treatment was recorded in the site file. This was a double-blind study in which the patient and the entire clinical team were blinded to the treatment assignment throughout. All analysis was undertaken blindly by a

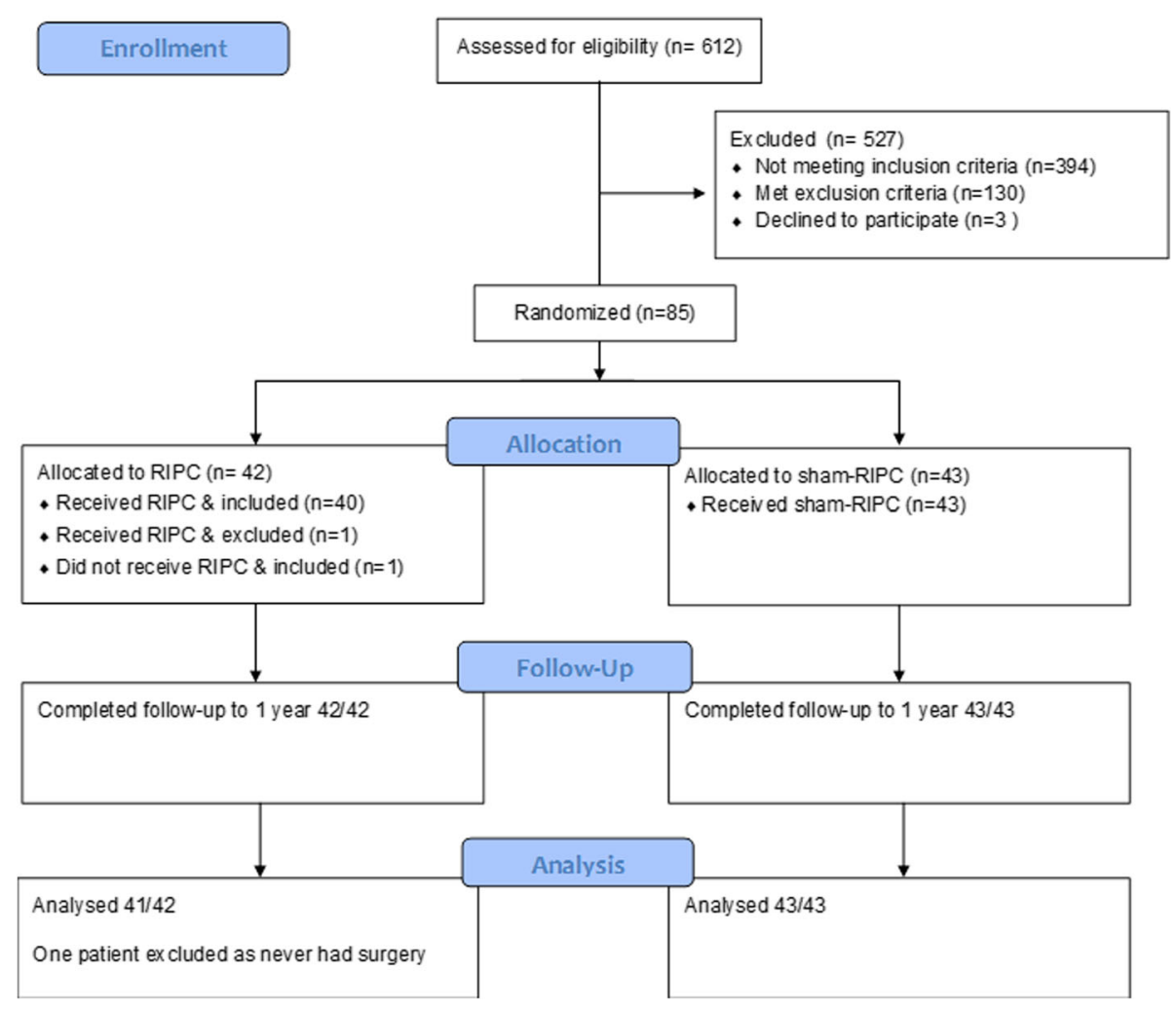

Fig. 1 CONSORT flowchart of participant allocation and progress 
non-operational co-author (TW, treatment assignments recoded to "A" and "B").

\section{Statistical methods}

Continuous group characteristics were described by median and interquartile range and compared with Mann-Whitney U-test (MWU); categorical variables were described by frequency and groups compared with Fisher's exact test. Peak and timepoint post-operative hs-TnT were compared with MWU, and hs-TnT curve integrals were compared using parametric tests. Analysis was by intention-to-treat. Predictors of PMI were discovered using chi-squared tests. Analysis was undertaken in SPSS (version 22, IBM, Armonk, NY, USA).

\section{Results}

Participants

Between October 2013 - December 2015, from a total of 612 screened general surgical patients, 85 were recruited to the study and randomized to RIPC (42) or sham-RIPC (43) (see Fig. 1). The main reason for exclusion was projected stay $\leq 1$ night. One patient was withdrawn after randomization as she developed a severe bradycardia at induction prior to receiving the RIPC treatment, leading to cancellation of surgery and thus could not participate. Participants generally underwent major colorectal resections or large bowel anastomoses after emergency surgery (see Table 1). Other operations included splenectomy (2), sleeve gastrectomy (2), and complex abdominal wall reconstruction (1). There were no differences in baseline indices between the

Table 1 Participant demographics

\begin{tabular}{|c|c|c|c|}
\hline Characteristic & Sham-RIPC $(n=43)$ & $\operatorname{RIPC}(n=41)$ & $P=$ \\
\hline${\text { Age, } \text { years }^{a}}$ & $60( \pm 15)$ & $65( \pm 12)$ & $0.261^{\dagger}$ \\
\hline Male sex & $25(65 \%)$ & $21(51 \%)$ & 0.271 \\
\hline $\mathrm{BMl}, \mathrm{kg} / \mathrm{m}^{2} \mathrm{a}$ & $25.5(22.8,31.1)$ & $27.0(22.5,29.3)$ & $0.589^{\ddagger}$ \\
\hline Abnormal baseline ECG & $9(21 \%)$ & $5(12 \%)$ & 0.385 \\
\hline Pre-op Creatinine $(\mu \mathrm{mol} / \mathrm{L})^{\mathrm{a}}$ & $81( \pm 20)$ & $76( \pm 17)$ & $0.431^{\dagger}$ \\
\hline \multicolumn{4}{|l|}{ Cardiac RFs } \\
\hline Hypercholesterolaemia & $8(19 \%)$ & $6(15 \%)$ & 0.772 \\
\hline Hypertension & $11(26 \%)$ & $11(27 \%)$ & 1 \\
\hline $\mathrm{FHx} I \mathrm{HD}$ & $8(19 \%)$ & $8(19 \%)$ & 1 \\
\hline Ex/current smoking & $29(67 \%)$ & $21(49 \%)$ & 0.182 \\
\hline Coronary Artery Disease & $5(12 \%)$ & $1(2 \%)$ & 0.202 \\
\hline Diabetes & $2(5 \%)$ & $3(7 \%)$ & 0.672 \\
\hline ASA & & & 0.714 \\
\hline । & $7(16 \%)$ & $5(12 \%)$ & \\
\hline$\|$ & $29(67 \%)$ & $29(71 \%)$ & \\
\hline III & $7(16 \%)$ & $6(15 \%)$ & \\
\hline IV & 0 & $1(2 \%)$ & \\
\hline Maintenance anaesthesia & & & 0.645 \\
\hline Propofol & $3(7 \%)$ & $4(10 \%)$ & \\
\hline Desflurane & $40(93 \%)$ & $37(90 \%)$ & \\
\hline Surgical procedure & & & 0.857 \\
\hline Small Bowel & $3(7 \%)$ & $5(12 \%)$ & \\
\hline Right hemicolectomy & $12(28 \%)$ & $11(27 \%)$ & \\
\hline Left hemicolectomy & $1(2 \%)$ & 0 & \\
\hline Rectum or sigmoid colon & $21(49 \%)$ & $19(46 \%)$ & \\
\hline Colectomy/Proctocolectomy & $3(7 \%)$ & $4(10 \%)$ & \\
\hline Other & $3(7 \%)$ & $2(5 \%)$ & \\
\hline
\end{tabular}

$B M I$ body mass index, ECG electrocardiogram, FHx IHD family history of ischaemic heart disease

${ }^{a}$ Descriptives given as counts (percentages), except for continuous data, which is given as mean ( \pm standard deviation), or median (25\% percentile, 75\% percentile)

$P$-values calculated with Fisher's exact test, ${ }^{\dagger}$ Student's t-test, or ${ }^{\ddagger}$ Mann-Whitney U-test 
treatment arms (see Table 1). All 84 patients were successfully followed-up to 1 year.

\section{Outcomes}

A total of 394 hs-TnT values were collected, 3.7 post-operative results per patient. PMI was recorded in 9/41 patients (22\%) in the RIPC group and 9/43 patients (21\%) in the sham-RIPC group $(P=1.000)$ indicating that RIPC did not influence PMI incidence. The mean peak post-operative hs-TnT concentration in those with PMI in the RIPC cohort was $25.65 \mathrm{ng} / \mathrm{L}$ (standard deviation (SD) 9.33), and in the sham-RIPC cohort $23.91 \mathrm{ng} /$ L (SD 13.2, mean difference $1.73 \mathrm{ng} / \mathrm{L}$, 95\% confidence interval -9.7 to $13.1 \mathrm{ng} / \mathrm{L}, P=0.753$ ), indicating that RIPC did not affect PMI severity. The total mean hs-TnT area under the curve in those sustaining PMI was: RIPC $1.24 \mu \mathrm{g} / \mathrm{L}$ (SD $0.54 \mu \mathrm{g} / \mathrm{L}$ ) vs sham-RIPC $0.97 \mu \mathrm{g} / \mathrm{L}(\mathrm{SD} 0.35 \mu \mathrm{g} / \mathrm{L}$, mean difference $-0.27 \mu \mathrm{g} / \mathrm{L}$, 95\% confidence interval -0.92 to $0.39 \mu \mathrm{g} / \mathrm{L}, P=0.393$ ). There was no significant AUC mean difference at any individual timepoint either in all patients or the PMI group (see Fig. 2a and b), or in any secondary outcome (see Table 2). There were no reported adverse events attributable to the treatments. None of the seven patients who received propofol-based maintenance anesthesia developed a PMI, and so all patients who sustained PMI were maintained with desflurane.

Recent data suggests that hs-TnT values of $>5 \mathrm{ng} / \mathrm{L}$ after non-cardiac surgery are associated with $300 \%$ increase in mortality [3]. In light of this, hs-TnT curves were again assessed using this cut-off. It was found that the RIPC cohort had a non-significant lower incidence of PMI in the RIPC cohort ( $68 \%$ vs $81 \%, P=0.211$ ), and significantly lower early hs-TnT release $(12 \mathrm{~h}$ time-point, RIPC $5.5 \mathrm{ng} / \mathrm{L}$ (SD 5.5) vs sham $9.1 \mathrm{ng} / \mathrm{L}$ (SD 8.2), $P=0.033$, see Fig. 2c).

Associations between the pre-determined pre-operative characteristics and post-operative raised hs-TnT were also examined (see Table 3). On univariate analysis, increased hs-TnT was significantly associated with older patients, having $>3$ cardiac risk factors, and an abnormal baseline EKG. Intra-operative raised venous lactate $(>2 \mathrm{mmol} / \mathrm{L}$ ) was inversely associated with raised hs-TnT. Two patients were dead at 1 year, and both had post-operative hs-TnT values $>14 \mathrm{ng} / \mathrm{L}$.

\section{Discussion}

This was a randomized controlled trial designed to test whether RIPC can reduce PMI caused by elective major abdominal surgery. Within this cohort, RIPC was safe. Nearly a quarter of patients had a clinically significant PMI, supportive of several recent studies [1, 2, 28, 29]. However, RIPC did not affect PMI incidence or severity, or associated clinical outcomes. More recent outputs of

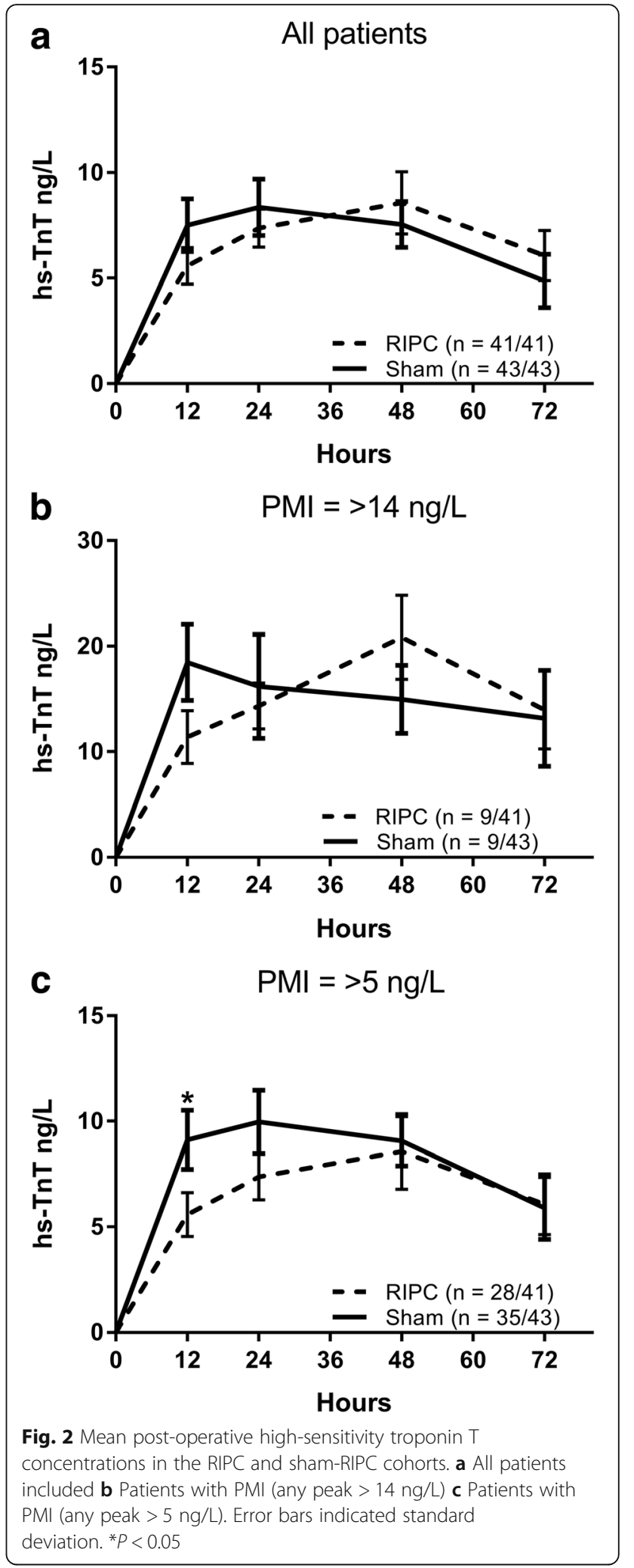


Table 2 Study outcomes

\begin{tabular}{|c|c|c|c|}
\hline & $\begin{array}{c}\text { Sham-RIPC } \\
(n=43)\end{array}$ & $\operatorname{RIPC}(n=41)$ & $P$ \\
\hline Peak hsTNT, n (\%) & & & 0.327 \\
\hline$<5 \mathrm{ng} / \mathrm{L}$ & $8(19 \%)$ & $13(31 \%)$ & \\
\hline 5-14 ng/L & $26(60 \%)$ & $19(46 \%)$ & \\
\hline$>14 \mathrm{ng} / \mathrm{L}$ & $9(21 \%)$ & $9(22 \%)$ & \\
\hline \multicolumn{4}{|l|}{ Mean peak hsTNT (ng/L) } \\
\hline All & $10.3(5.6,13.7)$ & $7.8(4.4,12.9)$ & 0.397 \\
\hline PMI (> 14 ng/L) & $17.1(16.5,29.0)$ & $20.5(17.0,35.0)$ & 0.387 \\
\hline $\mathrm{PMI}(>5 \mathrm{ng} / \mathrm{L})$ & $11.5(8.8,15.6)$ & $7.7(5.7,11.0)$ & 0.973 \\
\hline \multicolumn{4}{|l|}{ hsTnT AUC to $72 \mathrm{~h}$} \\
\hline All & $394(202,527)$ & $335(130,660)$ & 0.700 \\
\hline PMI (> 14 ng/L) & $868(559,1256)$ & $816(410,1050)$ & 0.711 \\
\hline PMI (> 5 ng/L) & $481(286,669)$ & $481(320,810)$ & 0.548 \\
\hline \multicolumn{4}{|l|}{ Secondary outcomes } \\
\hline MACCE to 1 year & $4(9 \%)$ & $1(2 \%)$ & 0.36 \\
\hline Surgical complication & $11(26 \%)$ & $8(20 \%)$ & 0.605 \\
\hline Length of stay & $6(4,9)$ & $5(3,8.5)$ & 0.472 \\
\hline Sympathomimetic use & $32(80 \%)$ & $27(73 \%)$ & 0.592 \\
\hline Venous lactate (mmol/L) & $1.5(1.0,2.1)$ & $1.2(0.9,1.75)$ & 0.288 \\
\hline Venous creatinine ( $\mu \mathrm{mol} / \mathrm{L})$ & $78(67,96)$ & $76(64,101)$ & 0.666 \\
\hline
\end{tabular}

Descriptives are count (percentage) and compared with chi squared tests, or median (25th percentile, 75th percentile) and compared with Mann-Whitney U test. MACCE major adverse cardiac and cerebrovascular events

the VISION collaboration suggests that absolute hs-TnT values of $>5 \mathrm{ng} / \mathrm{L}$ are associated with modest risk of mortality [3]. When the additional patients were included in the present analysis, RIPC significantly decreased the magnitude of hs-TnT at $12 \mathrm{~h}(P<0.033)$.

Promising animal studies [30], human randomized controlled trials $[16,31,32]$ and meta-analyses $[26,27]$ showed that RIPC can reduce the PMI associated with cardiac surgery. However, two meta-analyses have recently questioned whether RIPC affected clinical outcomes in this cohort [33, 34]. As the present study closed, two international RCTs (ERRICA and RIPHeart) powered to differences in detect a composite clinical outcome after cardiac surgery failed to show a treatment benefit for RIPC, both in terms of clinical and biochemical endpoints $[14,15]$. The neutral findings of RIPC in the present study may be explained by (i) the pathophysiology of myocyte injury in this surgical context is not influenced by RIPC (ii) no pre-specification of anesthesia (iii) inadequate definition of PMI in this surgical context.

To our knowledge, this is the first randomized controlled trial to address whether RIPC can influence PMI in patients undergoing inpatient abdominal surgery. The study was limited by the lack of available data on treatment effects in this surgical setting, so surrogate data
Table 3 Risk factors for elevated hs-TnT

\begin{tabular}{|c|c|c|c|}
\hline & No PMI & PMl & $P^{\dagger}=$ \\
\hline Age $>70$ & $17(26 \%)$ & $12(63 \%)$ & $0.005^{* *}$ \\
\hline Male & $35(55 \%)$ & $14(74 \%)$ & 0.187 \\
\hline $\mathrm{BMI}>30$ & $13(23 \%)$ & $5(29 \%)$ & 0.749 \\
\hline \multicolumn{4}{|l|}{ Cardiac RFs } \\
\hline 0 & $3(5 \%)$ & 0 & 1.000 \\
\hline 1 & $35(54 \%)$ & $12(63 \%)$ & 0.423 \\
\hline 2 & $17(26 \%)$ & $2(10 \%)$ & 0.339 \\
\hline 3 & $7(11 \%)$ & $1(5 \%)$ & 1.000 \\
\hline$>3$ & $3(5 \%)$ & $4(21 \%)$ & $0.035^{*}$ \\
\hline \multicolumn{4}{|l|}{ Pre-operative test } \\
\hline Abnormal ECG & $8(13 \%)$ & $6(32 \%)$ & $0.049^{*}$ \\
\hline Creatinine (> $120 \mu \mathrm{mol} / \mathrm{L})$ & $25(39 \%)$ & $3(16 \%)$ & 0.156 \\
\hline \multicolumn{4}{|l|}{ Operative events } \\
\hline $\mathrm{HR} \times 2$ normal & $4(7 \%)$ & $2(12 \%)$ & 0.616 \\
\hline MAP $\times 0.5$ normal & $8(13.8 \%)$ & $3(16 \%)$ & 1 \\
\hline Lactate $>1.5$ & $14(24 \%)$ & $1(5 \%)$ & 0.098 \\
\hline Surgery $>4 \mathrm{~h}$ & $32(55 \%)$ & $12(63 \%)$ & 0.602 \\
\hline Sympathomimetic use & $43(74 \%)$ & $16(84 \%)$ & 0.535 \\
\hline \multicolumn{4}{|l|}{ Post-operative events } \\
\hline Average length of stay (days) & 8 & 8 & 1 \\
\hline Dead at 30 days & 0 & 0 & - \\
\hline Dead at 1 year & 0 & $2(12 \%)$ & $0.044^{*}$ \\
\hline
\end{tabular}

${ }^{\dagger} P$ values calculated with Fisher exact or Mann-Whitney $\mathrm{U}$ test

from cardiac surgery was used, adjusting for PMI incidence in general surgery using VISION data. The second potential limitation is that anesthesia was not pre-specified. There is limited evidence from dog and human studies that propofol maintenance abrogates the RIPC effect [23,35], and it is interesting that the small group of propofol-only patients did not develop PMI. In 90\% ERRICA and 100\% RIPHeart participants, anesthesia was solely propofol-based. Advocates of RIPC have suggested that volatile anesthesia may yield different results [36, 37]. However, there was still no RIPC benefit in those with PMI ( $>14 \mathrm{ng} / \mathrm{L}$ ), who all received volatile anesthesia.

Several studies have found PMI to be common after inpatient abdominal procedure, and that it predicts mortality $[1,28,38,39]$. Confounding influences such as infective respiratory disease, renal impairment, and concurrent use of diuretics and anticoagulants are not fully characterized [40]. In this study, pre-existing infection was an exclusion criterion, and the other factors were not associated with raised hs-TnT (see Table 3). In keeping with previous studies [38, 41], factors predictive of risk were age and abnormal pre-operative cardiac tests, suggesting genuine and presumably modifiable 
myocyte pathology. Thus, two lines of future investigation are proposed (i) perioperative studies using alternative cardioprotective therapies to reduce PMI (ii) post-operative therapeutic studies in which the presence of PMI stratifies to long-term risk reduction. Although RIPC may not be efficacious in treating PMI in the present general surgery study population, it may yet hold value in certain high-risk contexts, for example in oesophageal resections.

\section{Conclusion}

RIPC was not effective in reducing PMI in this patient cohort. Perioperative myocardial injury in elective major abdominal surgery is common, and simple measures to provide cardioprotection are needed.

\section{Additional file}

Additional file 1: Study definitions. (DOCX $34 \mathrm{~kb}$ )

\section{Abbreviations}

AUC: area under the curve; EKG: Electrocardiogram; MWU: Mann-Whitney Utest; ns-TNT: high sensitivity troponin T; PMI: perioperative myocardial injury; RIPC: remote ischaemic preconditioning; SD: Standard deviation

\section{Acknowledgements}

The authors would like to thank Victoria Murray and James Reed for their assistance with recruitment, and Raja Jayaram for manuscript advice.

\section{Funding}

Costs for biochemistry were met by a departmental charitable fund.

\section{Availability of data and materials}

The anonymized dataset is currently available by reasonable request from the corresponding author.

\section{Authors' contributions \\ SA: study conception \& design, data collection, writing and drafting of manuscript; DC, NJ, AB: patient recruitment, data collection and analysis; TW and JH: Study design, data anlaysis, drafting of manuscript; AK: study design, oversight, manuscript drafting; DCoull study design, oversight, patient recruitment, manuscript drafting; AW study conception, design, oversight and drafting of manuscript. All authors read and approved the final manuscript.}

\section{Ethics approval and consent to participate}

The Berkshire 2 National Research Ethics Service provided ethical approval for the study (Reference: 13/SC/0306). Written informed consent was obtained from each participant prior to any data collection or study intervention.

\section{Competing interests}

The authors declare that they have no competing interests.

\section{Publisher's Note}

Springer Nature remains neutral with regard to jurisdictional claims in published maps and institutional affiliations.

\section{Author details}

${ }^{1}$ Department of Surgery, Royal Berkshire NHS Foundation Trust, Reading, UK. ${ }^{2}$ Intensive Care and Anaesthetics, Royal Berkshire NHS Foundation Trust, London Road, Reading RG1 5AN, UK. ${ }^{3}$ London Surgical Research Group, Reading, UK.
Received: 26 January 2018 Accepted: 24 May 2018

Published online: 26 June 2018

\section{References}

1. Devereaux PJ, Chan MT, Alonso-Coello P, Walsh M, Berwanger O, Villar JC, et al. The VISION study investigators. Association between postoperative troponin levels and 30-day mortality among patients undergoing noncardiac surgery. JAMA. 2012;307:2295-304.

2. Noordzij PG, Van Geffen O, Dijkstra IM, Boerma D, Meinders AJ, Rettig TCD, et al. High-sensitive cardiac troponin T measurements in prediction of noncardiac complications after major abdominal surgery. Br J Anaesth. 2015; 114:909-18

3. Devereaux PJ, Biccard BM, Sigamani A, Xavier D, Chan MTV, Srinathan SK, et al. Association of Postoperative High-Sensitivity Troponin Levels with Myocardial Injury and 30-day mortality among patients undergoing noncardiac surgery. JAMA. 2017;317:1642.

4. Kristensen DS, Knuuti J, Saraste A, Anker S, Erik Bøtker H, De Hert S. 2014 ESC/ESA guidelines on non-cardiac surgery: cardiovascular assessment and management. Eur Heart J. 2014;35(35):2383-431.

5. Devereaux PJ, Mrkobrada M, Sessler DI, Leslie K, Alonso-Coello P, Kurz A, et al. Aspirin in patients undergoing noncardiac surgery. N Engl J Med. 2014; 370:1494-503.

6. Devereaux PJ, Yang H, Yusuf S, Guyatt G, Leslie K, Villar JC, et al. Effects of extended-release metoprolol succinate in patients undergoing non-cardiac surgery (POISE trial): a randomised controlled trial. Lancet. 2008;371:1839-47.

7. Hindler K, Shaw AD, Samuels J, Fulton S, Collard CD, Riedel B. Improved postoperative outcomes associated with preoperative statin therapy. Anesthesiol. 2006;105:1260-72. -90

8. Dunkelgrun M, Boersma E, Schouten O, Koopman-van Gemert AWMM, van Poorten F, Bax JJ, et al. Bisoprolol and Fluvastatin for the reduction of perioperative cardiac mortality and myocardial infarction in intermediaterisk patients undergoing noncardiovascular surgery. Ann Surg. 2009;249: 921-6.

9. Kharbanda RK, Mortensen UM, White PA, Kristiansen SB, Schmidt MR, Hoschtitzky JA, et al. Transient limb ischemia induces remote ischemic preconditioning in vivo. Circ. 2002;106:2881-3.

10. Hausenloy DJ, Yellon DM. The therapeutic potential of ischemic conditioning: an update. Nat Rev Cardiol. 2011;8:619-29.

11. Chen M, Zhang M, Zhang $X$, Li J, Wang $Y$, Fan $Y$, et al. Limb ischemic preconditioning protects endothelium from oxidative stress by enhancing Nrf2 translocation and upregulating expression of Antioxidases. PLoS One. 2015;10:e0128455.

12. Hussein AM, Harraz AM, Awadalla A, Barakat N, Khater S, Shokeir AA. Remote limb ischemic preconditioning (rIPC) activates antioxidant and antiapoptotic genes and inhibits proinflammatory cytokine genes in renal ischemia/reperfusion injury. Gen Physiol Biophys. 2016:35:77-86.

13. Javadov SA, Clarke S, Das M, Griffiths EJ, Lim KHH, Halestrap AP. Ischaemic preconditioning inhibits opening of mitochondrial permeability transition pores in the reperfused rat heart. J Physiol. 2003;549(Pt 2):513-24.

14. Hausenloy DJ, Candilio L, Evans R, Ariti C, Jenkins DP, Kolvekar S, et al. Remote ischemic preconditioning and outcomes of cardiac surgery. N Engl J Med. 2015:373:1408-17.

15. Meybohm P, Bein B, Brosteanu O, Cremer J, Gruenewald M, Stoppe C, et al. A multicenter trial of remote ischemic preconditioning for heart surgery. $\mathrm{N}$ Engl J Med. 2015;373:1397-407.

16. Hausenloy DJ, Mwamure PK, Venugopal V, Harris J, Barnard M, Grundy E, et al. Effect of remote ischaemic preconditioning on myocardial injury in patients undergoing coronary artery bypass graft surgery: a randomised controlled trial. Lancet. 2007:370:575-9.

17. Zarbock A, Schmidt C, Van Aken H, Wempe C, Martens S, Zahn PK, et al. Effect of remote ischemic preconditioning on kidney injury among high-risk patients undergoing cardiac surgery. JAMA. 2015;313:2133.

18. Ali ZA, Callaghan CJ, Lim E, Ali AA, Nouraei SAR, Akthar AM, et al. Remote ischemic preconditioning reduces myocardial and renal injury after elective abdominal aortic aneurysm repair: a randomized controlled trial. Circ. 2007; 116(11 SUPPL):|98-105.

19. Rennie D. CONSORT revised-improving the reporting of randomized trials. JAMA. 2001;285:2006-7.

20. Cleveland JC, Meldrum DR, Cain BS, Banerjee A, Harken AH. Oral sulfonylurea hypoglycemic agents prevent ischemic preconditioning in human myocardium. Circ. 1997;96:29-32. 
21. Li F, Yuan Y. Meta-analysis of the cardioprotective effect of sevoflurane versus propofol during cardiac surgery. BMC Anesthesiol. 2015;15:128.

22. Ansley DM, Raedschelders K, Choi PT, Wang B, Cook RC, Chen DDY. Propofol cardioprotection for on-pump aortocoronary bypass surgery in patients with type 2 diabetes mellitus (PRO-TECT II): a phase 2 randomizedcontrolled trial. Can J Anesth Can d'anesthésie. 2016;63:442-53.

23. Kottenberg E, Thielmann M, Bergmann L, Heine T, Jakob H, Heusch G, et al. Protection by remote ischemic preconditioning during coronary artery bypass graft surgery with isoflurane but not propofol - a clinical trial. Acta Anaesthesiol Scand. 2012;56:30-8.

24. De Hert S, Vlasselaers D, Barbé R, Ory J-P, Dekegel D, Donnadonni R, et al. A comparison of volatile and non volatile agents for cardioprotection during on-pump coronary surgery. Anaesthesia. 2009;64:953-60.

25. Giannitsis E, Kurz K, Hallermayer K, Jarausch J, Jaffe AS, Katus HA. Analytical validation of a high-sensitivity cardiac troponin T assay. Clin Chem. 2010;56: 254-61.

26. Yang $L$, Wang $G$, Du Y, Ji B, Zheng Z. Remote ischemic preconditioning reduces cardiac troponin i release in cardiac surgery: a meta-analysis. J Cardiothorac Vasc Anesth. 2014;28:682-9.

27. D'Ascenzo F, Cavallero E, Moretti C, Omedè P, Sciuto F, I a R, et al. Remote ischaemic preconditioning in coronary artery bypass surgery: a metaanalysis. Heart. 2012;98:1267-71.

28. Kavsak PA, Walsh M, Srinathan S, Thorlacius L, Buse GL, Botto F, et al. High sensitivity troponin $T$ concentrations in patients undergoing noncardiac surgery: a prospective cohort study. Clin Biochem. 2011;44:1021-4.

29. Devereaux PJ. Characteristics and short-term prognosis of perioperative myocardial infarction in patients undergoing noncardiac surgery: a cohort study. Ann Intern Med. 2011;154:523-8.

30. Przyklenk K, Bauer B, Ovize M, Kloner RA, Whittaker P. Regional ischemic "preconditioning" protects remote virgin myocardium from subsequent sustained coronary occlusion. Circ. 1993:87:893-9.

31. Thielmann M, Kottenberg E, Kleinbongard P, Wendt D, Gedik N, Pasa S, et al. Cardioprotective and prognostic effects of remote ischaemic preconditioning in patients undergoing coronary artery bypass surgery: a single-centre randomised, double-blind, controlled trial. Lancet. 2013;382: 597-604.

32. Candilio L, Malik A, Ariti C, Barnard M, Di Salvo C, Lawrence D, et al. Effect of remote ischaemic preconditioning on clinical outcomes in patients undergoing cardiac bypass surgery: a randomised controlled clinical trial. Heart. 2015;101:185-92.

33. Brevoord D, Kranke P, Kuijpers M, Weber N, Hollmann M, Preckel B. Remote ischemic conditioning to protect against ischemia-reperfusion injury: a systematic review and meta-analysis. PLoS One. 2012;7:1-11.

34. Healy DA, Khan WA, Wong CS, Moloney MC, Grace PA, Coffey JC, et al. Remote preconditioning and major clinical complications following adult cardiovascular surgery: systematic review and meta-analysis. Int I Cardiol. 2014;176:20-31.

35. Bautin AE, Galagudza MM, Datsenko SV, Tashkhanov DM, Marichev AO, Bakanov Al, et al. Effects of remote ischemic preconditioning on perioperative period in elective aortic valve replacement. Anesteziol Reanimatol. 2014;(3):11-7. PMID 25306677.

36. Heusch G, Gersh BJ. ERICCA and RIPHeart: two nails in the coffin for cardioprotection by remote ischemic conditioning? Probably not! Eur Heart J. 2016;37:200-2.

37. Cheung $C X$, Healy DA, Walsh SR. Remote preconditioning and cardiac surgery: regrouping after remote ischemic preconditioning for heart surgery (RIPHeart) and effect of remote ischemic preconditioning on clinical outcomes in patients undergoing coronary artery bypass surgery (ERICCA). J Thorac Dis. 2016;8:E197-9.

38. Pearse RM, Moreno RP, Bauer P, Pelosi P, Metnitz P, Spies C, et al. Mortality after surgery in Europe: a 7 day cohort study. Lancet. 2012;380:1059-65.

39. Devereaux PJ, Xavier D, Pogue J, Guyatt G, Sigamani A, Garutti I, et al. Characteristics and short-term prognosis of perioperative myocardial infarction in patients undergoing noncardiac surgerya cohort study. Ann Intern Med. 2011;154:523-8.

40. Gorgun E, Lan BY, Aydinli HH, Reed GW, Menon V, Sessler DI, et al. Troponin elevation after colorectal surgery: significance and management. Ann Surg. 2016;264:605-11.

41. Gupta PK, Gupta H, Sundaram A, Kaushik M, Fang X, Miller WJ, et al. Development and validation of a risk calculator for prediction of cardiac risk after surgery. Circ. 2011;124:381-7.

\section{Ready to submit your research? Choose BMC and benefit from:}

- fast, convenient online submission

- thorough peer review by experienced researchers in your field

- rapid publication on acceptance

- support for research data, including large and complex data types

- gold Open Access which fosters wider collaboration and increased citations

- maximum visibility for your research: over $100 \mathrm{M}$ website views per year

At BMC, research is always in progress.

Learn more biomedcentral.com/submissions 